\title{
Evaluation of Environmental Worldview from the Perspectives of Undergraduate Students in N. Cyprus
}

\author{
Buket Asilsoy ${ }^{1}$, Selin Laleci ${ }^{1}$, Sinem Yildırım ${ }^{1}$, Kozan Uzunoğlu ${ }^{2}$, \\ Özge Özden Fuller ${ }^{1}$
}

\begin{abstract}
In recent years, environmental issues have been under considerable debate within the scientific community. In this context, environmental worldview has become a significant area of focus. In the light of recent studies it is understood that there are disparate variables influencing environmental worldview. Additionally it has been suggested that environmental worldview is a variable influencing environmental behaviour itself. As it is a significant aspect among the younger generations to adopt an environmentally responsible lifestyle, this study aimed at understanding the impact of several demographic variables such as gender and nationality on environmental worldview. In this research, environmental behaviour is further examined within the university students in Nicosia. A total number of 111 undergraduate students were chosen for this research. In the first section, several subjects were asked about their environmental knowledge and awareness. In the second section, with the help of Dunlop and Van Liere's New Environmental Paradigm (NEP) scale, environmental attitudes of participants were measured, in order to understand the level of their existing worldview.
\end{abstract}

Keywords: Environmental Worldview, NEP Scale, Survey, Undergraduate Students, Nicosia, Cyprus

\section{Introduction}

Beginning in the 1850's, after the Industrial Revolution of the late 1700's, the history of modern environmentalism began. Within the agenda of environmentalism for many years, the focus has primarily been placed on physical aspects such as waste management, public transportation and so forth. Within this perspective, existing physical environments of many cities have been enhanced and new developments have been planned in order to create sustainable and ecologically responsive environments. However especially after the 1980's it was determined that residents who have adopted an ecologically oriented way of living, would enhance and fulfill all these efforts. Thus, it is hypothesized that residents with sustainable lifestyles who are conscious about healthy living, walking, cycling, energy saving, local taste and food, sustainable public transportation, green economy etc., would have great significance and priority for paving the way towards an ecologically based, sustainable community. Within this framework, by examining and evaluating socio-psychological and socio-cultural dimensions and focusing on daily practices, lifestyles, attitudes and behaviours of different social groups in urban communities has received a great deal of attention. In this context, environmental worldview is a significant focus area and derived from a considerable 
amount of studies it can be suggested that the "environmental worldview" based on attitudes as value orientations, are among the most significant variables influencing environmental action (Ajzen and Fishbein, 1980; Fielding et al., 2008; Ogunbode, 2013). It is of significant importance among the younger generations to adopt an environmentally responsive lifestyle, this study aimed at obtaining scientific data from university students's existing environmental worldview and their environmental behaviours. Therefore, environmental knowledge regarding particular environmental issues, environmental worldview, environmental behaviours within different categories and socio-demographic variables are measured and examined within the university students of Nicosia.

The paper first provides a review of the relevant literature. Secondly, the methodology including sample and measures are presented, and survey findings displayed. Finally, the findings are interpreted and recommendations are made for further research.

\section{Theoretical Background Environmental Attitudes}

In the context of environmental behaviour literature, three sorts of attitudes as value orientation have been identified: egoistic, social altruistic (buman altruistic) and biocentric (ecocentric) environmental attitudes (Schwartz, 1977; Stern, Dietz and Kalof, 1993; Schultz, 2001). Egoistic values are based on self interest. In other words, egoistic environmental attitudes are based on the influence of the environment on individual's self and selforiented aims. Social altruistic (buman altruistic) environmental attitudes have a focus on human benefits or human goals. Biocentric attitudes has value orientations centered on the inherent value of the natural environment. In other words, the moral consideration is based on the well-being of nature.

Additionally there are researchers who propose two sorts of attitude as value orientation instead of three, in relation to environmental issues. Within this perspective, egoistic and social altruistic (buman altruistic) dimensions merge into a single dimension in which the human being would be the center of the relation. Thus, anthropocentric individuals would value the environment because of its contribution to the quality of human life. Another motive is the ecocentric (biocentric) environmental attitude. According to the ecocentric view, the individual and the environment would be on equal terms, forming a unit.

There have been several measures seeking to examine environmental attitudes. Among these instruments, Dunlop and Van Liere's New Environmental Paradigm (NEP) scale has almost become the most widely used scientific tool evaluating the environmental attitudes, beliefs, values and worldview.

\section{The New Environmental Paradigm (NEP) Scale}

The NEP scale appears as a set of general beliefs (worldview) regarding the domain of human-nature relationships that fits into the causal chain between relatively stable central elements of personality (personal values) and variables (such as awareness of the consequences of environmental change, perceived ability to influence and personal 
norms that create a predisposition regarding pro-environmental behaviour) that more directly influence an individual's behaviour with respect to the environment (Goldman et al., 2014).

The NEP scale was originally based on a scale of 12 items (Dunlop and Van Liere, 1978). It was revised and a scale with 15 items was developed (Dunlop et al., 2000). The revised NEP scale achieves five facets (reality of limits-to-growth, anti-anthropocentrism, fragility of nature's balance, rejection of exemptionalism and likelihood of eco-crisis). Odd numbered items $(1,3,5,7,9,11,13,15)$ reflects an ecocentric stance and even numbered items $(2,4,6,8,10,12,14)$ reflects an anthropocentric stance. Table 1 displays these 15 items; three items were designed to tap each of the five hypothesized facets of an ecological worldview.

Table 1: Revised New Environmental Paradigm (NEP) Items (Source: Dunlop et al., 2000)

NEP Facets Scale Items

The reality of limits to 1 .We are approaching the limit of the number of people the earth can growth support

6. The earth has plenty of natural resources if we only learn how to develop them

11. The earth is like a spaceship with very limited room and resources

Antianthropocentrism 2. Humans have the right to modify the natural environment to suit their needs

7. Plants and animals have as much right as humans to exist.

12. Humans were meant to rule the rest of nature.

The fragility of 3 . When humans interfere with nature it often produces disastrous nature's balance consequences

8. The balance of nature is strong enough to cope with the impact of modern industrial nations

13. The balance of nature is very delicate and easily upset

Rejection exemptionalism

of 4. Human ingenuity will insure that we do NOT make the earth unliveable

9. Despite our special abilities, humans are still subject to the laws of nature

14. Humans will eventually learn enough about how nature works to be able to control it.

The possibility of an 5. Humans are severely abusing the environment

ecological crisis

10. The so-called ecological crisis facing humankind has been exaggerated

15. If things continue on their present course, we will soon experience a major ecological catastrophe 


\section{Environmental Behaviour}

Although it diverges according to the focus of the researchers, it can be argued that the activities and actions that can be defined as environmentally responsive can be grouped in six behavioural categories (Asilsoy and Derya, 2016).

Energy saving: Keeping heating low to save energy, using double glazed windows for buildings, using energy efficient appliances and whitegoods, reducing hot water temperature, using more clothes instead of more heating, switching lights off in unused rooms, reducing heat in unused rooms, using high efficiency bulbs, using building insulation.

Water conservation: Using a shower instead of a bath, turning tap off when soaping up, turning tap off when washing dishes, turning tap off when cleaning teeth, using plants that need less water, reducing the number of baths/showers, reducing toilet flushes etc.

Waste management: Recycling plastic bottles, composting garden waste, recycling cans, recycling glass, recycling newspaper, reusing glass, donating furniture and clothes to charity, reusing paper, reducing battery usage, composting kitchen waste etc.

Public participation: Involving in environmental decision making process, involving in environmental campaigns, being an environmental activist etc.

Sustainable transportation: Using public transportation instead of car, walking in short distances, carpooling, using a bicycle rather than a car etc.

Green consumption: Buying locally produced foods, using own bag for shopping, buying recycled toilet paper, less packaging, buying organic products, avoiding aerosols and toxic detergents, buying recycled writing paper, buying from a local store etc.

\section{Methodology Research Design}

The aspects of this research were part of a questionnaire including a set of questions which were answered under four main titles. These titles were as follows: environmental concern; environmental attitudes; environmental behaviours; sociodemographic data. The first section of the questionnaire involved seven qualitatively designed items. With the help of these items, it was aimed at obtaining data about the respondents' awareness and concern for environmental issues such as 'biodiversity', 'global warming and climate change' etc. Ecocentric and anthropocentric attitudes were examined in the second section in order to provide data for the existing value orientations. In the third section, environmental behaviour was examined with the help of six items. In the fourth section, socio-demographic data was collected in order to obtain information about age, gender etc. of the respondents.

\section{The Sample}

A random sample of 111 undergraduate students having three distinct nationality profiles was chosen for filling out a questionnaire form. 37 students chosen were from the Turkish Republic of Northern Cyprus (TRNC) nationality. The next 37 
respondents were undergraduate students possessing Turkish Republic (TR) nationality. And the final 37 participants were international students. Almost nine participants of each nationality category from the first, second, third and fourth academic year of the Near East University Faculty of Architecture Department of Architecture students were randomly. The details are shown below.

Gender: Of the 111 respondents in the research $25.2 \%$ were female and $74.8 \%$ were male in total. From the international students $27.03 \%$ were female and $72.97 \%$ were male. From the TR students, $16.22 \%$ were female and $83.78 \%$ were male. Of the TRNC students $32.43 \%$ were female and $67.57 \%$ were male.

Table 2 Participants' gender profile (\%)

\begin{tabular}{|l|l|l|}
\hline Participants & Female & Male \\
\hline Foreign Students & $27.03 \%$ & $72.97 \%$ \\
\hline TR Students & $16.22 \%$ & $83.78 \%$ \\
\hline TRNC Students & $32.43 \%$ & $67.57 \%$ \\
\hline
\end{tabular}

Age: The majority of the respondents $(71.17 \%)$ were between the ages of $16-25$, with a further of them $(27.03 \%)$ between the ages of $26-40$. The rest $(1.8 \%)$ were $41-55$ years old. See Table 3 for details.

Table 3 Participants' age profile (\%)

\begin{tabular}{|l|l|l|l|}
\hline Participants & $\mathbf{1 6 - 2 5}$ & $\mathbf{2 6 - 4 0}$ & $\mathbf{4 1 - 5 5}$ \\
\hline Foreign Students & $67.57 \%$ & $32.43 \%$ & - \\
\hline TR Students & $56.76 \%$ & $37.84 \%$ & $5.4 \%$ \\
\hline TRNC Students & $89.19 \%$ & $10.81 \%$ & - \\
\hline
\end{tabular}

Household income: $9.43 \%$ of the respondents had a monthly household income of 6001199TL. 30.19\% had a monthly household income of 1200-2499TL. $21.70 \%$ of the students had a monthly household income of 2500-3999TL. 17.93\% had a monthly household income of 4000-5999TL. And 20.75\% had a monthly household income of 6000 TL+. A breakdown of the three groups monthly income can be seen in Table 4.

Table 4 Participants' household financial situation profile (\%)

\begin{tabular}{|l|l|l|l|l|l|}
\hline Participants & $\mathbf{6 0 0 - 1 1 9 9 T L}$ & $\mathbf{1 2 0 0 - 2 4 9 9 T L}$ & $\mathbf{2 5 0 0 - 3 9 9 9 T L}$ & $\mathbf{4 0 0 0 - 5 9 9 9 T L}$ & $\mathbf{6 0 0 0}$ TL+ \\
\hline Foreign Students & $5.41 \%$ & $13.51 \%$ & $21.62 \%$ & $21.62 \%$ & $37.84 \%$ \\
\hline TR Students & $13.51 \%$ & $37.85 \%$ & $27.02 \%$ & $10.81 \%$ & $10.81 \%$ \\
\hline TRNC Students & $9.36 \%$ & $40.63 \%$ & $15.63 \%$ & $21.88 \%$ & $12.5 \%$ \\
\hline
\end{tabular}

\section{Measures}

Environmental worldview: The environmental attitudes were measured with the help of NEP (New Environmental Paradigm) scale including 15 items (Dunlop et al., 2000) in 
the second section of the questionnaire. These NEP scale items were used to measure the ecocentric and anthropocentric attitudes. According to the NEP scale design, one of the statements refers to an ecocentric attitude and the other refers to an anthropocentric attitude. In total, eight items refer to ecocentric attitude and the other seven items refer to anthropocentric attitude. A Likert type five point scale (strongly disagree to strongly agree) was used to record the participants' responses for each item.

Environmental behaviours: Environmental behaviours were measured with the help of six items in order to understand how often the respondents were performing these environmental behaviours in and around the home during their daily lives. A five point frequency scale (from never to always) was used to record the participants' responses to each item.

\section{Procedure}

After participants were briefly informed about the research, environmental awareness and concern about general environmental issues were measured in the questionnaire's first section. Ecocentric and anthropocentric attitudes were examined in the second section in order to provide data for the existing value orientations. In the third section, environmental behaviours about energy saving, water conservation and green consumption etc. were examined. In the final section, socio-demographic data was collected in order to obtain information about the issues such as age, gender etc.

\section{Results}

The mean score of the NEP scale was measured at 3.06. The mean score of the foreign students was measured as 2.83 . The mean score of the students from Turkish Republic was measured as 3.21 and the mean score of the students from Turkish Republic of Northern Cyprus was calculated as 3.15.

As it is accepted that a NEP mean score of 3 is the boundary between an anthropocentric and ecocentric worldview (Rideout et al., 2005; Van Petegam and Blieck, 2006), the result showed that the respondents had slightly a medium level of ecological worldview in total. In other words, the results imply that the sample have an indecisive stance regarding an ecological worldview. The students holding relatively stronger ecological views than the others are from Turkish Republic. The students holding the least ecological views are from the foreign countries.

Next, the findings of the questionnaire's third section which involves six items about environmental behaviors in and around home was evaluated. The results are displayed below. 
Table 5 Foreign students' responses to the environmental behaviour items (\%)

\begin{tabular}{|l|l|l|l|l|l|}
\hline Environmental Behaviour Items & Always & Usually & $\begin{array}{l}\text { Somet } \\
\text { imes }\end{array}$ & Rarely & Never \\
\hline I used papers double-sided as much as possible. & $13.51 \%$ & $18.92 \%$ & $\begin{array}{l}40.54 \\
\%\end{array}$ & $21.62 \%$ & $5.41 \%$ \\
\hline I switch lights off in unused rooms. & $18.92 \%$ & $27.03 \%$ & $\begin{array}{l}29.73 \\
\%\end{array}$ & $18.92 \%$ & $5.41 \%$ \\
\hline I turn tap off while cleaning teeth. & $24.32 \%$ & $13.51 \%$ & $\begin{array}{l}35.14 \\
\%\end{array}$ & $21.62 \%$ & $5.41 \%$ \\
\hline I prefer to give my unused clothes, furniture etc. & $27.03 \%$ & $21.62 \%$ & $\begin{array}{l}27.03 \\
\%\end{array}$ & $21.62 \%$ & $2.70 \%$ \\
\hline $\begin{array}{l}\text { Instead of plastic or packaged products, I prefer to } \\
\text { take a less packed. }\end{array}$ & $10.80 \%$ & $16.22 \%$ & $\begin{array}{l}37.84 \\
\%\end{array}$ & $18.92 \%$ & $16.22 \%$ \\
\hline $\begin{array}{l}\text { I prefer to buy rechargeable batteries instead of } \\
\text { disposable. }\end{array}$ & $62.16 \%$ & $21.62 \%$ & $8.11 \%$ & $8.11 \%$ & - \\
\hline
\end{tabular}

When we evaluate the results of the foreign students' responses about the environmental behaviour items, it can be argued that the most agreement was about the item 'T prefer to buy rechargeable batteries instead of disposable'. $62.16 \%$ of them replied 'always' and $21.62 \%$ replied 'usually' to this item. The least agreement was about the item 'I used papers doublesided as much as possible', such that merely 13.51\% replied 'always' and 18.92\% replied 'usually' to this item.

Table 6 TR students' responses to the environmental behaviour items (\%)

\begin{tabular}{|l|l|l|l|l|l|}
\hline Environmental Behaviour Items & Always & Usually & $\begin{array}{l}\text { Someti } \\
\text { mes }\end{array}$ & Rarely & Never \\
\hline I used papers double-sided as much as possible. & $54.05 \%$ & $27.03 \%$ & $16.22 \%$ & - & $2.7 \%$ \\
\hline I switch lights off in unused rooms. & $78.38 \%$ & $13.51 \%$ & $2.7 \%$ & - & $5.41 \%$ \\
\hline I turn tap off while cleaning teeth. & $44.44 \%$ & $11.11 \%$ & $22.23 \%$ & $11.11 \%$ & $11.11 \%$ \\
\hline $\begin{array}{l}\text { I prefer to give my unused clothes, furniture } \\
\text { etc. }\end{array}$ & $30.55 \%$ & $27.78 \%$ & $16.67 \%$ & $13.89 \%$ & $11.11 \%$ \\
\hline $\begin{array}{l}\text { Instead of plastic or packaged products, I } \\
\text { prefer to take a less packed. }\end{array}$ & $27.03 \%$ & $10.81 \%$ & $29.73 \%$ & $18.92 \%$ & $13.51 \%$ \\
\hline $\begin{array}{l}\text { I prefer to buy rechargeable batteries instead of } \\
\text { disposable. }\end{array}$ & $35.13 \%$ & $29.73 \%$ & $16.22 \%$ & $5.41 \%$ & $13.51 \%$ \\
\hline
\end{tabular}

When we evaluate the results of the TR students' responses about the environmental behaviour items, it can be argued that the most agreement was about the item I switch lights off in unused rooms'. $78.38 \%$ replied 'always' and $13.51 \%$ replied 'usually' to this item. Another strong agreement was about the item 'I used papers double-sided as much as possible'. $54.05 \%$ replied 'always' and $27.03 \%$ replied 'usually' to this item. Additionally the least agreement of the TR students was about the item 'Instead of plastic or packaged products, I prefer to take a less packed'. $27.03 \%$ replied always and $10.81 \%$ replied usually to this item. 
Table 7 TRNC students' responses to the environmental behaviour items (\%)

\begin{tabular}{|l|l|l|l|l|l|}
\hline Environmental Behaviour Items & Always & Usually & $\begin{array}{l}\text { Someti } \\
\text { mes }\end{array}$ & Rarely & Never \\
\hline $\begin{array}{l}\text { I used papers double-sided as much as } \\
\text { possible. }\end{array}$ & & & & & \\
\hline I switch lights off in unused rooms. & $45.95 \%$ & $32.43 \%$ & $18.92 \%$ & - & $2.7 \%$ \\
\hline $\begin{array}{l}\text { I turn tap off while cleaning teeth. } \\
\text { I prefer to give my unused clothes, furniture }\end{array}$ & $40.54 \%$ & $18.92 \%$ & $32.43 \%$ & $5.41 \%$ & $2.7 \%$ \\
\hline $\begin{array}{l}\text { Instead of plastic or packaged products, I } \\
\text { prefer to take a less packed. }\end{array}$ & $43.24 \%$ & $27.03 \%$ & $24.32 \%$ & $5.41 \%$ & - \\
\hline $\begin{array}{l}\text { I prefer to buy rechargeable batteries instead of } \\
\text { disposable. }\end{array}$ & $27.03 \%$ & $16.22 \%$ & $27.03 \%$ & $\begin{array}{l}13 \% \\
\%\end{array}$ & $16.22 \%$ \\
\hline
\end{tabular}

When we evaluate the results of the TRNC students' responses about the environmental behaviour items, it can be argued that the most agreement was about the item ' $I$ used papers double-sided as much as possible'. 62.16\% replied always and 18.92\% replied usually to this item. The least agreement of the TRNC students was about the item 'Instead of plastic or packaged products, I prefer to take a less packed'. Merely $27.03 \%$ of them replied 'always' and $16.22 \%$ replied 'usually'.

According to these results, it can be suggested that in general, the respondents do not have a strong commitment of ecological view. Such that the item 'Instead of plastic or packaged products, I prefer to take a less packed'was among the items with the least agreement for Turkish and Cypriot students. However this item of green consumption needs a strong environmental commitment. Additionally foreign students replied 'always' with a high percentage $(62.16 \%)$ to the item I prefer to buy rechargeable batteries instead of disposable, as another item requiring a strong commitment. On the contrary these foreign students had the least agreement to the item 'I used papers double-sided as much as possible', as an item that do not require a high level of environmental concern.

\section{Conclusion and Discussion}

Residents with sustainable lifestyles are significant for paving the way towards an ecologically based, sustainable community. Particularly, it is crucial for the younger generations of the urban communities to adopt environmentally based lifestyles via their behaviours, daily activities and actions in their daily lives.

On that ground, a user survey is prepared in order to understand the dynamics of university students' environmental worldview and environmental behaviours. The environmental attitudes constituting a worldview were measured with the help of Dunlop and Van Liere's New Environmental Paradigm scale. This scale has almost become the most widely used scientific tool evaluating the environmental attitudes, beliefs, values and worldview. And environmental behaviours were measured with the help of six items in order to understand how often the respondents were performing 
these environmental behaviours in and around the home in their daily lives.

According to the results the respondents have a slightly medium level of environmental worldview. As the students will face enormous challenges of sustainability issues in their careers, it would be eligible to adopt a higher level of environmental worldview. In other words, as they are the generations experiencing ecological crisis both in their countries and worldwide i.e global warming and climate change etc., it is therefore an urgent issue for younger students to have a commitment to adopting an ecological worldview and an ecologically responsive lifestyle. Therefore further research is eligible to understand the dynamics of environmental attitudes, beliefs, values and behaviours of urban residents within different social groups. The data obtained could be used for policies aimed at the value-based and behavioural change that will lead us to a more sustainability oriented way of living. Hence such policy strategies appear as an urgent need for the future of the planet.

\section{References}

Ajzen, I., and Fishbein, M. (1980). Understanding Attitudes and Predicting Social Behaviour. Englewood Cliffs, NJ (New Jersey): Prentice Hall.

Fielding, K. S., Terry, D. J., Masser, B. M., and Hogg, M. A. (2008). "Integrating Social Identity Theory and the Theory of Planned Behaviour to Explain Decisions to Engage in Sustainable Agricultural Practices." British Journal of Social Psychology 47: 23-48.

Ogunbode, C. A. (2013). “The NEP Scale: Measuring Ecological Attitudes/Worldviews in an African Context." Environment, Development and Sustainability 15: 1477-94.

Schwartz, S. H. (1977). Normative influences on altruism, In L. Berkowitz (Ed), Advances in Experimental Social Psychology, 10, 221-279, New York Academic Press.

Stern, P., Dietz, T., \& Kalof, L. (1993) Value orientations, gender and environmental concern, Environment and Behaviour, 25 (5), 322-348.

Schultz, P. W. (2001). The structure of environmental concern: Concern for self, other people, and the biosphere, Journal of Environmental Psychology, 21, 327-339.

Goldman D., Assaraf O. B., \& Shemesh J. 2014. 'Human nature': Chemical engineering student's ideas about human relationships with the natural world, European Journal of Engineering Education, Vol:39, No:3, 325-347.

Dunlap, R. E., Van Liere, K., Mertig, A., \& Jones, R. E. (2000). Measuring endorsement of the New Ecological Paradigm: A revised NEP scale, Journal of Social Issues, 56, 425-442.

Dunlap, R. E., Van Liere, K. (1978). The 'New Environmental Paradigm': A proposed measuring instrument and preliminary results, Journal of Environmental Education, 9, pp 10-19.

Asilsoy B., \& Oktay D. (2016). Environmental Attitudes as Predictors of Ecological Citizenship: Findings from a Survey in Famagusta, North Cyprus, Open House International (Special Issue on Transformations of Architecture and Urbanism of Cities in the Global South, Eds: A. Salama \& D. Grierson), Volume 41, Issue 2, June 2016 (accepted for publication).

Rideout, B. E., Hushen, K., McGinty, D., Perkins, S., \& Tate, J. (2005). Endorsement of the environmental paradigm in systematic and e-mail samples of college students, Journal of Environmental Education, 36 (2), 15-23.

Van Petegam, P., \& Blieck, A. (2006). The environmental worldview of children: A cross-cultural perspective. Environmental Education Research, 12, 625-635. 